\title{
Population-Based Analysis of Nonoperative Management and Treatment Patterns in Older Women with Estrogen Receptor-Positive Breast Cancer
}

\section{David Tejera}

Lady Davis Institute for Medical Research

Mariam Rana

Segal Cancer Centre

Mark Basik

Segal Cancer Centre Jean Francois Boileau

Segal Cancer Centre

Richard Margolese

Segal Cancer Centre

Ipshita Prakash

Segal Cancer Centre

Ari N. Meguerditchian

McGill University Health Centre

Thierry Muanza

Sir Mortimer B Davis Jewish General Hospital

Johanne Monette

Jewish General Hospital: Sir Mortimer B Davis Jewish General Hospital

Stephanie M Wong ( $\square$ sm.wong@mcgill.ca )

Segal Cancer Centre https://orcid.org/0000-0002-6850-2192

\section{Research Article}

Keywords: Breast neoplasms, elderly, hormone-positive breast cancer, sentinel lymph node biopsy, radiation therapy

Posted Date: February 8th, 2021

DOI: https://doi.org/10.21203/rs.3.rs-178697/v1 
License: (c) (i) This work is licensed under a Creative Commons Attribution 4.0 International License. Read Full License 


\section{Abstract}

Purpose: To examine the proportion of older women with ER+HER2- breast cancer receiving non-operative management versus surgery, and to evaluate the use of axillary staging and adjuvant radiation in this population.

Methods: We queried the SEER database to identify all women aged 70 years or older with stage I-III ER+HER2- invasive breast cancer diagnosed between 2010-2016. We evaluated trends in non-operative management, breast surgery, axillary staging, and adjuvant radiation according to age at diagnosis.

Results: We identified 57,351 older women with ER+HER2- disease. Overall, 3538 (6.2\%) of the cohort underwent non-operative management, 38,452 (67.0\%) underwent breast conserving surgery (BCS), and 15,361 (26.8\%) underwent mastectomy. The proportion of patients undergoing non-operative management increased from $2.8 \%$ amongst $70-74$ year old women to $30.1 \%$ in those ${ }^{3} 90$ years old $(p<0.001)$. In 53,813 women who underwent surgery, 36,850 (68.5\%) underwent sentinel lymph node biopsy, while 10,861 (20.2\%) underwent axillary lymph node dissection. Subgroup analysis of 29,032 older women undergoing BCS for stage I ER+HER2- breast cancer revealed a $14.2 \%$ rate of omission of axillary staging, increasing from $5.3 \%$ in those $70-74$ years to $67.6 \%$ in those ${ }^{390}$ years old $(p<0.001)$. Receipt of adjuvant radiation occurred in $63.3 \%$ of older women following BCS and $18 \%$ postmastectomy, with similar trends towards omission in older age groups.

Conclusion: Primary breast surgery remains the dominant management strategy for the majority of older women with ER+HER2- breast cancer. Omission of axillary staging and adjuvant radiation are used in a minority of eligible women undergoing breast conservation for early-stage disease.

\section{Introduction}

One third of women affected with breast cancer are over the age of 70 at the time of diagnosis. Relative to younger women, older women are significantly more likely to have estrogen-receptor positive, HER2/ neu negative (ER + HER2-) breast cancers and to be diagnosed with stage II-III disease.[1] However, due to the presence of comorbidities, older women, particularly those over 80 years of age, are also more likely to be treated with non-operative management that includes primary endocrine therapy. $[2,3]$ In those who are eligible to undergo surgery, data from prospective clinical trials suggest that it is safe to omit axillary staging and adjuvant radiation without compromising overall survival. $[4,5]$

Practice management strategies vary widely for older women with ER + HER2- breast cancer as this patient population is inherently heterogeneous. $[6,7]$ This can present a clinical challenge for health care providers, who must take into account chronologic and biological age, overall functional status, and residual life expectancy when making treatment decisions.[8, 9] Moreover, due to substantial gains in life expectancy over the last several decades, women living to 80 years of age can now expect a lifespan of 10 years, while women living to 90 years can expect 5.5 additional years of life.[10] As a result, care must 
be taken not to over- or undertreat these patients, the latter of which can result in poorer breast-cancer specific survival.[11]

There is currently a paucity of data evaluating modern trends in local therapy for older women, particularly those older than 80 or 90 years of age. In this study, we sought to evaluate treatment patterns over the last decade in older patients with ER + HER2- breast cancer. Our goal was to examine the proportion of older patients with ER + HER2- breast cancer receiving non-operative management versus upfront surgery, and in those undergoing surgery, to evaluate the use of axillary staging and adjuvant radiation by age at diagnosis.

\section{Methods}

\section{Data Source and Patient Selection}

We evaluated a cohort of patients from the publicly available records of 18 population-based cancer registries in the Surveillance, Epidemiology, and End Results (SEER) Radiation/Chemotherapy Treatment database. SEER is an authoritative source for cancer statistics, collecting data on cancer diagnoses, primary treatment, and survival with a catchment area that covers approximately $28 \%$ of the United States population. The November 2018 submission was used for this study, with all patients censored on December 31, 2016. For cohort selection, women aged 70 years or older with a first diagnosis of histologically-confirmed breast cancer were abstracted from SEER. We retained all cases with stage I-III ER + HER2- breast cancer diagnosed between the years 2010 and 2016; prior to this period, data on HER2/ neu status were not available. Women for whom histologic grade, nodal status, or staging information was not reported were then excluded from the analysis.

\section{Outcome of Interest}

Our primary outcome of interest was the proportion of patients receiving nonoperative management for $\mathrm{ER}+\mathrm{HER} 2$ - breast cancer. The reason for omitting surgery of the primary tumor was obtained from the 'Reason no cancer-directed surgery' variable in SEER. For those undergoing surgery, surgical management was categorized as breast conserving surgery (BCS) or mastectomy. Women who underwent the following surgical procedures were considered to have undergone BCS: partial mastectomy, partial mastectomy with nipple resection, lumpectomy, excisional biopsy, re-excision of biopsy site, and segmental mastectomy. Those undergoing total (simple) mastectomy, modified radical mastectomy, mastectomy NOS, or nipple-sparing ('subcutaneous') mastectomy were considered to have undergone mastectomy.

Our secondary outcome of interest was the use of axillary staging and radiation, particularly in women undergoing BCS. Axillary staging was determined using surrogate values with extent of disease codes for the number of regional lymph nodes examined; women with 1-5 lymph nodes removed were considered to have undergone sentinel lymph node biopsy (SLNB) whereas women with $>5$ lymph nodes removed were placed within the axillary lymph node dissection (ALND) group, as has been done in previous 
studies.[12] Adjuvant radiation therapy was defined as "received" versus "no radiation/unknown if received radiation" due to stated limitations and sensitivity of this variable reported by SEER.[13]

\section{Independent Variables of Interest}

Independent variables of interest included demographic variables such as age at diagnosis, marital status, race, and SEER region. Tumor histology, histologic grade, and pathologic characteristics such as tumor size and nodal status were also obtained. The American Joint Commission of Cancer (AJCC) 7th edition staging system was used to define patients with stage I-III disease.

\section{Statistical Analysis}

Statistical comparisons between groups were performed using Pearson's Chi-squared or Fisher's exact tests for categorical data and Wilcoxon Rank sum test for continuous data. According to age at diagnosis, the proportion of patients undergoing non-operative management, axillary surgery, and adjuvant radiation were compared using the Mantel-Haensel test for trend. To examine the implementation of clinical trial results, $[4,5]$ subgroup analysis was performed to examine axillary surgery and adjuvant radiation trends in older women with AJCC 7th edition Stage I (T1N0 or T1Nx) ER + HER2breast cancer undergoing BCS. Multivariable logistic regression models were then constructed to calculate the adjusted odds ratio (OR) for receipt of non-operative management in all patients, as well as receipt of axillary surgery (defined as SLNB or ALND), and adjuvant radiation in those undergoing surgical management. In addition to the independent variables listed above, year of diagnosis was included as a variable in all adjusted analyses in order to account for temporal trends. Indicator variables were created for missing data and included in the model for analysis. All analyses were performed using SAS version 9.4 (SAS Institute, Cary, NC) with all $p$-values two-sided and a $p<0.05$ used to indicate statistical significance.

\section{Results}

\section{Cohort Characteristics}

We identified 57,351 women aged 70 years or older with ER + HER2- disease who met inclusion and exclusion criteria and were eligible for study. The majority of patients were Caucasian (77.6\%), with stage I (66.2\%) disease and invasive ductal histology (70.9\%). (Table 1) With respect to age, $38,595(67.0 \%)$ patients were between $70-79$ years old, 16,374 (28.6\%) were between $80-89$ years old, and $2382(4.2 \%)$ were over the age of 90 years old at the time of diagnosis. Overall, $3538(6.2 \%)$ of the cohort underwent non-operative management with omission of surgery, 38,452 (67.0\%) underwent BCS, and 15,361 (26.8\%) underwent mastectomy.

\section{Factors associated with Non-operative Management in Older Women}


The proportion of patients undergoing non-operative management for ER + HER2-breast cancer increased from $2.8 \%$ of women between $70-74$ years to $30.1 \%$ of women over 90 years of age $(p<0.001$, Fig. 1$)$. Factors independently associated with patients receiving non-operative management included age, marital status, geographic region, and AJCC stage. (Table 2) In adjusted analyses, age remained the strongest predictor of non-operative management. Compared to women aged 70-74 years old, women aged $80-84$ years old were 2.54 -fold ( $95 \% \mathrm{Cl} 2.27-2.84)$, more likely to undergo nonoperative management, while women over the age of 90 were 13-fold more likely (OR 12.93, 95\% $\mathrm{Cl} 11.4-14.7$ ). Relative to married women, women who were widowed (OR 1.38, 95\% $\mathrm{Cl} 1.26-1.51$ ) or single (OR 1.58, $95 \% \mathrm{Cl} 1.42-1.76)$ were modestly more likely to undergo non-operative management. Finally, more advanced disease was also independently associated with a significantly higher odds of primary nonoperative management (Stage III OR 3.68, 95\% Cl 3.24-4.17). (Table 2)

Overall, the majority of the cohort that underwent non-operative management did so because surgery was not recommended by their providers $(n=2040,57.6 \%)$ or contraindicated due to co-morbid conditions ( $n$ $=470,13.3 \%)$. In addition, $222(6.3 \%)$ patients refused surgery, and an additional $28(0.8 \%)$ died before recommended surgery could take place. In the remaining 632 patients $(17.9 \%)$, the reason for nonoperative management was not documented.

\section{Axillary Staging in Older Women Undergoing Surgery}

In the 53,813 women who underwent surgery for ER + HER2- breast cancer, 36,850 (68.5\%) underwent axillary staging with SLNB, while 10,861 (20.2\%) underwent ALND. In the group of 15,361 women undergoing mastectomy, $95.0 \%$ of patients underwent some form of surgical axillary staging with SLNB or ALND. In the minority of mastectomy patients (5.0\%) who did not undergo axillary surgery, age remained a significant predictor for omission $(p<0.001)$. (Fig. $2 A)$

In the 38,452 women undergoing BCS, 28,628 (74.5\%) patients underwent SLNB, 4493 (11.7\%) patients underwent ALND, and 5331 (13.9\%) patients underwent omission of axillary staging. There was also a trend towards omission of axillary staging in older age groups, increasing from $4.8 \%$ in 70-74 year old patients to $21 \%$ in the $80-84$ year old age group, and to $65.9 \%$ of patients undergoing BCS at 90 years or older ( $\mathrm{p}$ <.001). (Fig. 2B) In multivariable analysis adjusting for demographic and clinical variables, relative to women aged $70-74$ years at diagnosis, women aged $80-84$ years were $80 \%$ less likely to receive surgical axillary staging during breast conservation (OR $0.19,95 \% \mathrm{Cl} 0.18-0.21$ ) whereas women over 90 years old were $97 \%$ less likely to undergo axillary surgery (OR $0.03,95 \% \mathrm{Cl} 0.02-0.03)$.

In subgroup analysis of 29,032 older patients with stage I ER + HER2- breast cancer undergoing BCS, the rates of omission of axillary surgery were similar (14.2\%), with the majority of patients preferentially receiving SLNB for staging the axilla from ages 70-89 years old, after which omission of nodal staging became the dominant axillary management strategy. (Fig. 2C)

\section{Adjuvant Radiation in Older Women}


Overall, adjuvant radiation occurred in 24,336 (63.3\%) older women following breast conservation, while post-mastectomy radiation occurred in 2765 (18\%) older women. Age remained a significant factor for receipt of adjuvant radiation following BCS. Approximately $74.4 \%$ of patients in the $70-74$ years old age group received adjuvant radiation therapy, decreasing steadily with age such that $52.7 \%$ of $80-84$ year old patients and only $15 \%$ of women over 90 years received adjuvant whole breast radiation (Fig. $3 \mathrm{~A}$ ). In adjusted analysis, adjuvant radiation was more common in younger patients, as well as those with pathologic characteristics including invasive lobular carcinoma (OR 1.41, 95\% $\mathrm{Cl} 1.32-1.50$ ), high grade histology (OR 1.28, 95\% Cl 1.19-1.36), large tumor size (pT3, OR 2.59, 95\% 2.29-2.92) and node positive disease. In those that were node positive, increasing nodal burden resulted in an increased odds of receiving adjuvant radiation ( $\mathrm{pN} 1, \mathrm{OR} 2.16,95 \% \mathrm{Cl}$ 2.02-2.30; pN2, OR 5.74, 95\% Cl 5.08-6.50).

\section{Discussion}

In this large cohort of women aged 70 years or older with ER + HER2- breast cancer diagnosed between 2010 and 2016 , we found that $6.2 \%$ of patients underwent non-operative management, while $26.8 \%$ underwent mastectomy and the remaining two-thirds of women underwent breast conservation. In those undergoing BCS, $86 \%$ received some form of axillary surgery, while $63 \%$ proceeded to adjuvant radiation therapy. Notably, we observed a de-escalation of local therapy with increasing age, with a tendency towards greater omission of SLNB and radiation following limited surgery in older age groups. This was most pronounced in patients aged 90 years or more, where non-operative management was selected in $30 \%$ of cases, and where omission of axillary surgery and adjuvant radiation was seen in the majority of women undergoing breast conservation, reported in $65 \%$ and $85 \%$, respectively.

The use of non-operative management with primary endocrine therapy in older women with ER + HER2breast cancer varies widely by geographic region and increases significantly with age. In the United Kingdom, Netherlands, and Ireland, surgery is omitted in $30 \%-40 \%$ of women aged 80 years or older and over half of women greater than 90 years of age.[14-16] In contrast, data from Germany, Belgium, and Switzerland suggest that primary surgery remains the dominant management strategy for the large majority of older women with breast cancer, including those above 90 years of age.[15] In North America, data from our study and other population-based registries suggest similar trends with primary surgery used preferentially in older women, although non-operative management has shown modest uptake in recent years.[17] Our study included 16,374 women 80 to 89 years, and in this population, $9.4 \%$ underwent non-operative management. In the 2,382 women aged 90 years and older, non-operative management was selected in $30.1 \%$ of cases. Interestingly, in two thirds of women managed nonoperatively, the reasoning behind their decision to omit surgery was related to provider recommendation or medical contraindications, with relatively few older women refusing surgery outside of said circumstances.

While early meta-analyses demonstrated equivalent overall survival outcomes amongst women managed with primary endocrine therapy versus surgery,[18] newer data suggests improved breast-cancer specific survival in women with ER + HER2- breast cancer treated with upfront surgery followed by endocrine 
therapy.[19] In the multi-centered, observational AGE GAP trial, women in the United Kingdom aged 70 years or older were followed prospectively following a diagnosis of estrogen-receptor positive breast cancer based on management strategy. Recent results reported by Wyld et al. demonstrated a nonsignificant difference in short-term survival outcomes amongst a propensity-matched cohort of 426 older women treated with surgery versus 240 women treated with primary endocrine therapy.[20] Of note, after 4 years, a divergence in survival favoring surgery occurred, leading the authors to suggest that primary endocrine therapy should be reserved for women with limited life expectancy of up to 4 years. The importance of appropriate patient selection and the need for close clinical surveillance has been reported in prior studies that caution around endocrine resistance after 2-3 years of primary endocrine therapy. [21] Given the likelihood of disease progression, these studies support a concerted and standardized effort to perform comprehensive geriatric assessments in order to accurately calculate life expectancy and tailor individual treatment recommendations.

For older women undergoing breast conservation for early-stage, ER + HER2- breast cancer, the omission of axillary surgery or adjuvant radiation has not been shown to alter overall survival. In the CALGB 9343 trial, Hughes et al. randomized 636 women aged 70 years or older with clinically node negative ER + breast cancer up to $2 \mathrm{~cm}$ in size to adjuvant radiation with Tamoxifen versus Tamoxifen alone.[4] In their trial, ALND was allowed but not encouraged, and as a result most older women did not undergo surgical nodal sampling.[22] At 10 years follow up, the addition of adjuvant radiation to endocrine therapy following lumpectomy decreased locoregional recurrences from $10-2 \%$, with no difference in overall survival. Furthermore, among those who did not undergo axillary surgery, there were no nodal recurrences in the radiation group and a 3\% 10-year axillary recurrence rate in the Tamoxifen only group. These findings and similar results from other trials[23, 24] led to the publication of the 2016 Society of Surgical Oncology (SSO) Choosing Wisely guidelines which recommended against the routine use of SLNB in older women with early-stage hormone receptor positive breast cancer. While further data on axillary surgery are needed to evaluate guideline adoption, population-based studies that pre-dated their publication suggest an increased uptake of axillary surgery in this population, with over $80 \%$ of older women receiving some form of surgical nodal staging.[25] In our subgroup analysis of CALGB 9343 eligible patients with stage I, ER + HER2- breast cancer treated between 2010 and 2016, we found similarly low rates of omission of SLNB, although this was more common amongst women aged 70-79 years of age. In those 80 years and older, omission of SLNB was seen in $29 \%$ of women, and in those over 90 years, two thirds of women avoided axillary staging with SLNB.

In the current study, adjuvant radiation was used in $63.3 \%$ of older women following breast conservation, while post-mastectomy radiation occurred in $18 \%$ of older women. After breast conservation, the use of radiation decreased steadily with age such that approximately half of 80-84 year-old patients and only $15 \%$ of women over 90 years received adjuvant whole breast radiation. These results validate findings from the National Cancer Database (NCDB) where Chu et al. reported octogenarians over 85 years old were less likely to receive adjuvant radiation therapy than those aged 70-74 years, and with advanced age, omission of adjuvant therapy was more common.[26] This was also demonstrated in another large NCDB study by Herskovic et al. who interestingly noted a five-year overall survival benefit in women over 
65 years of age with early stage HR + HER2- breast cancer who received adjuvant radiation therapy in addition to endocrine therapy, however this difference may have been explained by significant ageimbalances between radiation and non-radiation therapy groups $(p<0.001)$.[27] In another populationbased study of 53,532 South Korean patients, adjuvant radiation therapy had a statistically significant overall survival benefit in the control group of younger women, however adjuvant radiation therapy after BCS did not demonstrate a significant survival benefit in elderly patients $(p=0.123)$. [28] The lack of overall survival shown from population-based studies supports level 1 evidence from randomized controlled trials performed in the United States and the United Kingdom including CALGB 9343 and PRIME II trial. $[4,5,22]$ This also provides evidence as to why many clinicians believe that the use of adjuvant radiotherapy should be reserved to prevent early locoregional recurrences in older women at high risk due to large tumor size, high grade or node-positive ER + HER2- disease, or in triple negative and HER2-positive subtypes. With more convenient hypo-fractionated treatment schedules such as those put forward in the FAST-Forward trial becoming widely adopted, it remains important to avoid undertreatment in these select older women with high risk of local relapse.[29]

The strengths of this study include its large modern cohort of older women, as well as details regarding the reasons for non-operative management. However, our study has several limitations inherent to the use of large datasets. Firstly, within SEER there is the potential for information and misclassification bias, as well as limited information regarding important confounders such as medical comorbidities, functional status, and the use of endocrine therapy, which often contribute to local therapy decision making. Furthermore, minimal data were available regarding clinical presentation, patient versus physician preferences around surgery, preferences of caregivers, and adjuvant treatment decisions. Finally, although the SEER treatment database includes adjuvant radiotherapy information with a high positive predictive value of $97.6 \%$, the sensitivity is lower at $80 \%$, suggesting that the reported data may systematically under-estimate adjuvant radiation receipt.[13]

\section{Conclusion}

Although age is the strongest independent factor associated with non-operative management, primary breast surgery remains the dominant management strategy for the majority of older women with ER + HER2- breast cancer. Axillary staging and adjuvant radiation are omitted in only a minority of eligible women undergoing breast conservation for early-stage disease. Further studies are warranted to determine whether guideline adoption has influenced receipt of SLNB and adjuvant radiation, and whether these impact outcomes and quality of life in this older patient population.

\section{Declarations}

Funding: Stephanie M Wong supported by the Tomlinson Fund Academic Surgery Award.

Conflict of Interest: The authors have no conflicts of interest to declare. 
Ethics approval (include appropriate approvals or waivers): Waived by the Institutional Review Board of the Jewish General Hospital due to the use of anonymized, publicly available de-identified data.

Availability of data and material (data transparency): Data publicly available from the National Cancer Institute's SEER database.

Code availability (software application or custom code): Available upon request.

Authors' contributions: All authors contributed to the study conception and design. Material preparation, data collection and analysis were performed by David Tejera and Stephanie M Wong. The first draft of the manuscript was written by David Tejera and all authors commented on previous versions of the manuscript. All authors read and approved the final manuscript.

\section{References}

1. Howlader N, Altekruse SF, Li Cl, Chen VW, Clarke CA, Ries LA, Cronin KA: US incidence of breast cancer subtypes defined by joint hormone receptor and HER2 status. J Natl Cancer Inst 2014, 106(5)

2. Nayyar A, Strassle PD, lles K, Jameison D, Jadi J, McGuire KP, Gallagher KK: Survival Outcomes of Early-Stage Hormone Receptor-Positive Breast Cancer in Elderly Women. Ann Surg Onco/ 2020

3. Pepping RMC, Portielje JEA, van de Water W, de Glas NA (2017) Primary Endocrine Therapy in Older Women with Breast Cancer. Curr Geriatr Rep 6(4):239-246

4. Hughes KS, Schnaper LA, Bellon JR, Cirrincione CT, Berry DA, McCormick B, Muss HB, Smith BL, Hudis CA, Winer EP et al (2013) Lumpectomy plus tamoxifen with or without irradiation in women age 70 years or older with early breast cancer: long-term follow-up of CALGB 9343. J Clin Oncol 31(19):2382-2387

5. Kunkler IH, Williams LJ, Jack WJ, Cameron DA, Dixon JM, investigators PI: Breast-conserving surgery with or without irradiation in women aged 65 years or older with early breast cancer (PRIME II): a randomised controlled trial. Lancet Onco/2015, 16(3):266-273

6. Freedman RA (2015) Treatment of Breast Cancer in the Elderly. Curr Oncol Rep 17(11):51

7. Hamaker ME, Bastiaannet E, Evers D, Water W, Smorenburg CH, Maartense E, Zeilemaker AM, Liefers GJ, Geest L, de Rooij SE et al (2013) Omission of surgery in elderly patients with early stage breast cancer. Eur J Cancer 49(3):545-552

8. Enger SM, Thwin SS, Buist DS, Field T, Frost F, Geiger AM, Lash TL, Prout M, Yood MU, Wei F et al (2006) Breast cancer treatment of older women in integrated health care settings. J Clin Oncol 24(27):4377-4383

9. Hurria A, Levit LA, Dale W, Mohile SG, Muss HB, Fehrenbacher L, Magnuson A, Lichtman SM, Bruinooge SS, Soto-Perez-de-Celis E et al: Improving the Evidence Base for Treating Older Adults With Cancer. American Society of Clinical Oncology Statement. J Clin Oncol2015, 33(32):3826-3833

10. Canada S: Table 13-10-0134-01 Life expectancy at various ages, by population group and sex, Canada 
11. Schonberg MA, Marcantonio ER, Li D, Silliman RA, Ngo L, McCarthy EP (2010) Breast cancer among the oldest old: tumor characteristics, treatment choices, and survival. J Clin Oncol 28(12):2038-2045

12. Wang J, Mittendorf EA, Sahin AA, Yi M, Caudle A, Hunt KK, Wu Y (2014) Outcomes of sentinel lymph node dissection alone vs. axillary lymph node dissection in early stage invasive lobular carcinoma: a retrospective study of the surveillance, epidemiology and end results (SEER) database. PLoS One 9(2):e89778

13. Noone AM, Lund JL, Mariotto A, Cronin K, McNeel T, Deapen D, Warren JL (2016) Comparison of SEER Treatment Data With Medicare Claims. Med Care 54(9):e55-e64

14. Bastiaannet E, Liefers GJ, de Craen AJ, Kuppen PJ, van de Water W, Portielje JE, van der Geest LG, Janssen-Heijnen ML, Dekkers OM, van de Velde CJ et al (2010) Breast cancer in elderly compared to younger patients in the Netherlands: stage at diagnosis, treatment and survival in 127,805 unselected patients. Breast Cancer Res Treat 124(3):801-807

15. Kiderlen M, Bastiaannet E, Walsh PM, Keating NL, Schrodi S, Engel J, van de Water W, Ess SM, van Eycken L, Miranda A et al (2012) Surgical treatment of early stage breast cancer in elderly: an international comparison. Breast Cancer Res Treat 132(2):675-682

16. Lavelle K, Downing A, Thomas J, Lawrence G, Forman D, Oliver SE (2012) Are lower rates of surgery amongst older women with breast cancer in the UK explained by co-morbidity? Br J Cancer 107(7):1175-1180

17. Kantor O, Pesce C, Liederbach E, Wang CH, Winchester DJ, Yao K (2016) Surgery and hormone therapy trends in octogenarians with invasive breast cancer. Am J Surg 211(3):541-545

18. Hind D, Wyld L, Reed MW (2007) Surgery, with or without tamoxifen, vs tamoxifen alone for older women with operable breast cancer: cochrane review. Br J Cancer 96(7):1025-1029

19. Ward SE, Richards PD, Morgan JL, Holmes GR, Broggio JW, Collins K, Reed MWR, Wyld L (2018) Omission of surgery in older women with early breast cancer has an adverse impact on breast cancer-specific survival. Br J Surg 105(11):1454-1463

20. Wyld LRM, Collins K, Ward S, Holmes G, Morgan J, Bradburn M, Walters S, Burton M, Edwards A, Ring A, Rpbinson T, Martin C, Chater T, Permberton K, Cheung KL, Todd A, Audisio R, The Age Gap Trial Management Group.: Impacts of omission of breast cancer surgery in older women with ER + early breast cancer. A risk stratified analysis of survival and quality of life outcomes. In: 12th European Breast Cancer Conference: Presented October 2, 2020

21. Shachar SS, Hurria A, Muss HB (2016) Breast Cancer in Women Older Than 80 Years. Journal of oncology practice 12(2):123-132

22. Hughes KS, Schnaper LA, Berry D, Cirrincione C, McCormick B, Shank B, Wheeler J, Champion LA, Smith TJ, Smith BL et al (2004) Lumpectomy plus tamoxifen with or without irradiation in women 70 years of age or older with early breast cancer. N Engl J Med 351(10):971-977

23. International Breast Cancer Study G, Rudenstam CM, Zahrieh D, Forbes JF, Crivellari D, Holmberg SB, Rey P, Dent D, Campbell I, Bernhard J et al: Randomized trial comparing axillary clearance versus no 
axillary clearance in older patients with breast cancer: first results of International Breast Cancer Study Group Trial 10-93. J Clin Oncol 2006, 24(3):337-344

24. Martelli G, Boracchi P, Ardoino I, Lozza L, Bohm S, Vetrella G, Agresti R (2012) Axillary dissection versus no axillary dissection in older patients with T1NO breast cancer: 15-year results of a randomized controlled trial. Ann Surg 256(6):920-924

25. Louie RJ, Gaber CE, Strassle PD, Gallagher KK, Downs-Canner SM, Ollila DW (2020) Trends in Surgical Axillary Management in Early Stage Breast Cancer in Elderly Women: Continued OverTreatment. Ann Surg Oncol 27(9):3426-3433

26. Chu QD, Zhou M, Medeiros KL, Peddi P, Wu XC (2017) Impact of CALGB 9343 Trial and Sociodemographic Variation on Patterns of Adjuvant Radiation Therapy Practice for Elderly Women $(>/=70$ Years) with Stage I, Estrogen Receptor-positive Breast Cancer: Analysis of the National Cancer Data Base. Anticancer Res 37(10):5585-5594

27. Herskovic AC, Wu X, Christos PJ, Nagar H (2018) Omission of Adjuvant Radiotherapy in the Elderly Breast Cancer Patient: Missed Opportunity? Clin Breast Cancer 18(5):418-431

28. Jeon YW, You SH, Lee JE, Youn HJ, Lim W, Han JH, Park CH, Kim YS (2019) Optimal treatment of breast cancer in women older than 75 years: a Korea Breast Cancer Registry analysis. Breast Cancer Res Treat 178(3):693-701

29. Murray Brunt A, Haviland JS, Wheatley DA, Sydenham MA, Alhasso A, Bloomfield DJ, Chan C, Churn M, Cleator S, Coles CE et al (2020) Hypofractionated breast radiotherapy for 1 week versus 3 weeks (FAST-Forward): 5-year efficacy and late normal tissue effects results from a multicentre, noninferiority, randomised, phase 3 trial. Lancet 395(10237):1613-1626

\section{Tables}




\begin{tabular}{|c|c|}
\hline \multicolumn{2}{|c|}{$\begin{array}{l}\text { TABLE I Cohort Characteristics, SEER 2010-2016 }(\mathrm{n}= \\
57,351)\end{array}$} \\
\hline \multicolumn{2}{|l|}{ Characteristic } \\
\hline \multicolumn{2}{|l|}{ Age Group - $n,(\%)$} \\
\hline 70-74 years & 22681 (39.6) \\
\hline $75-79$ years & $15914(27.8)$ \\
\hline $80-84$ years & $10492(18.3)$ \\
\hline $85-89$ years & $5882(10.3)$ \\
\hline $90+$ years & $2382(4.2)$ \\
\hline \multicolumn{2}{|l|}{ Marital Status - $n,(\%)$} \\
\hline Married* & $24478(42.7)$ \\
\hline Widowed & 19494 (34.0) \\
\hline Single/Divorced/Separated & $10353(18.1)$ \\
\hline Unknown & $3026(5.3)$ \\
\hline \multicolumn{2}{|l|}{ Race $-n,(\%)$} \\
\hline White & $44505(77.6)$ \\
\hline Black & $4414(7.7)$ \\
\hline Hispanic & $4201(7.3)$ \\
\hline Asian/Pacific Islander & $3643(6.4)$ \\
\hline Other/Unknown & $588(1.0)$ \\
\hline \multicolumn{2}{|l|}{ SEER Region - $n,(\%)$} \\
\hline California $^{\dagger}$ & $23203(40.5)$ \\
\hline Georgia ${ }^{\ddagger}$, Louisiana, Kentucky & $12035(21.0)$ \\
\hline Connecticut, New Jersey & $8719(15.2)$ \\
\hline Seattle (Puget Sound), Hawaii, Alaska & $4997(8.7)$ \\
\hline Detroit, lowa & $5706(10.0)$ \\
\hline Utah, New Mexico & $2691(4.7)$ \\
\hline
\end{tabular}




\begin{tabular}{|c|c|}
\hline \multicolumn{2}{|c|}{$\begin{array}{l}\text { TABLE I Cohort Characteristics, SEER 2010-2016 ( } \mathrm{n}= \\
57,351)\end{array}$} \\
\hline \multicolumn{2}{|l|}{ Tumor histology - $n,(\%)$} \\
\hline Invasive Ductal Carcinoma & $40686(70.9)$ \\
\hline Invasive Lobular Carcinoma & $7368(12.9)$ \\
\hline Mixed Invasive Ductal \& Lobular & $6513(11.4)$ \\
\hline Other/Favorable histologies $^{\dagger}$ & $2784(4.9)$ \\
\hline \multicolumn{2}{|l|}{ Histologic grade $-n,(\%)$} \\
\hline Grade I & 19120 (33.3) \\
\hline Grade II & $29465(51.4)$ \\
\hline Grade III & $8766(15.3)$ \\
\hline \multicolumn{2}{|l|}{ Pathologic Tumor size, $\mathrm{cm}-n,(\%)$} \\
\hline $0-2.0 \mathrm{~cm}$ & $32249(56.2)$ \\
\hline $2.1-5.0 \mathrm{~cm}$ & $13172(23.0)$ \\
\hline$>5.0 \mathrm{~cm}$ & $2264(4.0)$ \\
\hline Unknown & $9666(16.9)$ \\
\hline \multicolumn{2}{|l|}{ Pathologic nodal status - $n,(\%)$} \\
\hline Negative & $37034(64.6)$ \\
\hline Positive & $11,476(20.0)$ \\
\hline Not examined/Unknown & 8841 (15.4) \\
\hline \multicolumn{2}{|l|}{ AJCC 7th edition stage $-n,(\%)$} \\
\hline Stage I & $37939(66.2)$ \\
\hline Stage II & $15651(27.3)$ \\
\hline Stage III & $3761(6.6)$ \\
\hline
\end{tabular}

*Including common law or domestic partner; ${ }^{\dagger}$ Includes San-Francisco-Oakland, San Jose-Monterey, Los Angeles, and Greater California; ${ }^{\ddagger}$ Includes Metropolitan Atlanta, Rural Georgia, and Greater Georgia; 
TABLE II Logistic Regression Analysis for Receipt of Nonoperative Management in Older Women with Stage I-III Hormone Receptor Positive, HER2-negative Breast Cancer $(n=57,351)$

\begin{tabular}{|c|c|c|c|c|}
\hline \multirow[t]{2}{*}{ Characteristic } & \multirow{2}{*}{$\begin{array}{l}\text { Cohort } \\
\text { No. } \\
\text { (\%) }\end{array}$} & \multicolumn{2}{|c|}{$\begin{array}{l}\text { Proportion with non- } \\
\text { operative management }\end{array}$} & \multirow{2}{*}{$\begin{array}{l}\text { Adjusted odds ratio for non } \\
\text { operative management } \\
(95 \% \mathrm{Cl})^{\star \star}\end{array}$} \\
\hline & & $\%$ & P-value & \\
\hline Age Group & & & $<0.001$ & \\
\hline $70-74$ years & 22681 & 2.8 & & 1.00 \\
\hline $75-79$ years & & 4.0 & & $1.45(1.29-1.62)$ \\
\hline $80-84$ years & $(27.8)$ & 6.9 & & $2.54(2.27-2.84)$ \\
\hline $85-89$ years & 10492 & 14.0 & & $5.33(4.76-5.98)$ \\
\hline \multirow[t]{3}{*}{$90+$ years } & $(10.0)$ & 30.1 & & $12.93(11.38-14.69)$ \\
\hline & $\begin{array}{l}5882 \\
(10.3)\end{array}$ & & & \\
\hline & $\begin{array}{l}2382 \\
(4.2)\end{array}$ & & & \\
\hline Marital Status & & & $<0.001$ & \\
\hline Married* & 24478 & 3.6 & & 1.00 \\
\hline Widowed & & 8.5 & & $1.38(1.26-1.51)$ \\
\hline \multirow[t]{2}{*}{ Single/Divorced/Separated } & $\begin{array}{l}19494 \\
(34.0)\end{array}$ & 6.4 & & $1.58(1.42-1.76)$ \\
\hline & $\begin{array}{l}10353 \\
(18.1)\end{array}$ & & & \\
\hline Race/Ethnicity & & & $<0.001$ & \\
\hline White & 44505 & 5.8 & & 1.00 \\
\hline Black & & 9.8 & & $0.99(0.88-1.12)$ \\
\hline Hispanic & $(7.7)$ & 6.5 & & $0.87(0.77-1.00)$ \\
\hline Asian/Pacific Islander & 4201 & 4.9 & & $0.97(0.85-1.11)$ \\
\hline \multirow{3}{*}{ Other/Unknown } & & 14.8 & & $0.75(0.52-1.08)$ \\
\hline & $\begin{array}{l}3643 \\
(6.4)\end{array}$ & & & \\
\hline & $\begin{array}{l}588 \\
(1.0)\end{array}$ & & & \\
\hline
\end{tabular}

*Including common law or domestic partner; ${ }^{\dagger}$ Includes San-Francisco-Oakland, San Jose-Monterey, Los Angeles, and Greater California; ${ }^{\ddagger}$ Includes Metropolitan Atlanta, Rural Georgia, and Greater Georgia; **Bold when statistically significant, $p<0.05$. 
TABLE II Logistic Regression Analysis for Receipt of Nonoperative Management in Older Women with Stage I-III Hormone Receptor Positive, HER2-negative Breast Cancer $(n=57,351)$

SEER Region

California $^{\dagger}$
Georgia $^{\ddagger}$, Louisiana,
Kentucky

Connecticut, New Jersey

Seattle (Puget Sound),

Hawaii, Alaska

Detroit, lowa

Utah, New Mexico$$
<0.001
$$

$\begin{array}{lll}23203 & 5.7 & 1.00 \\ (40.5) & 5.9 & 1.10(0.99-1.22) \\ 12035 & & 1.49(1.35-1.65) \\ (21.0) & 9.1 & 1.00(0.86-1.15) \\ 8719 & 5.3 & 1.01(0.88-1.15) \\ (15.2) & 5.6 & 1.60(1.37-1.88) \\ 4997 & & \\ (8.7) & 8.0 & \\ 5706 & & \\ (10.0) & & \\ 2691 & & \\ (4.7) & & \end{array}$

Tumor Histology $<0.001$

Invasive Ductal Carcinoma 40686 (70.9)

Invasive Lobular

Carcinoma

Mixed Invasive Ductal \& Lobular

Other/Favorable

histologies $^{\dagger}$

\section{8}

(12.9)

6.3

1.00

7.1

$0.95(0.85-1.05)$

$6513 \quad 5.0$

(11.4)

4.5

$0.64(0.56-0.73)$

2784

(4.9)

Histologic Grade

$$
<0.001
$$

Grade I

19120

(33.3)

Grade II 29465

Grade III

5.1

6.5

7.5

$0.70(0.58-0.84)$

1.00

$1.03(0.94-1.12)$

$0.93(0.83-1.04)$

*Including common law or domestic partner; ${ }^{\dagger}$ Includes San-Francisco-Oakland, San Jose-Monterey, Los Angeles, and Greater California; ${ }^{\ddagger}$ Includes Metropolitan Atlanta, Rural Georgia, and Greater Georgia; **Bold when statistically significant, $p<0.05$. 
TABLE II Logistic Regression Analysis for Receipt of Nonoperative Management in Older Women with Stage I-III Hormone Receptor Positive, HER2-negative Breast Cancer $(n=57,351)$

AJCC 7th Edition Stage $<0.001$

$\begin{array}{llll}\text { Stage I } & 37939 & 5.1 & 1.00 \\ \text { Stage II } & (66.2) & 7.2 & \mathbf{2 . 0 1}(\mathbf{1 . 8 3 - 2 . 2 1 )} \\ \text { Stage III } & 15651 & & \mathbf{3 . 6 8}(\mathbf{3 . 2 4}-\mathbf{4 . 1 7}) \\ & (27.3) & 12.8 & \\ & 3761 & & \\ (6.6) & & \end{array}$

*Including common law or domestic partner; ${ }^{\dagger}$ Includes San-Francisco-Oakland, San Jose-Monterey, Los Angeles, and Greater California; ${ }^{\ddagger}$ Includes Metropolitan Atlanta, Rural Georgia, and Greater Georgia; **Bold when statistically significant, $p<0.05$.

\section{Figures}

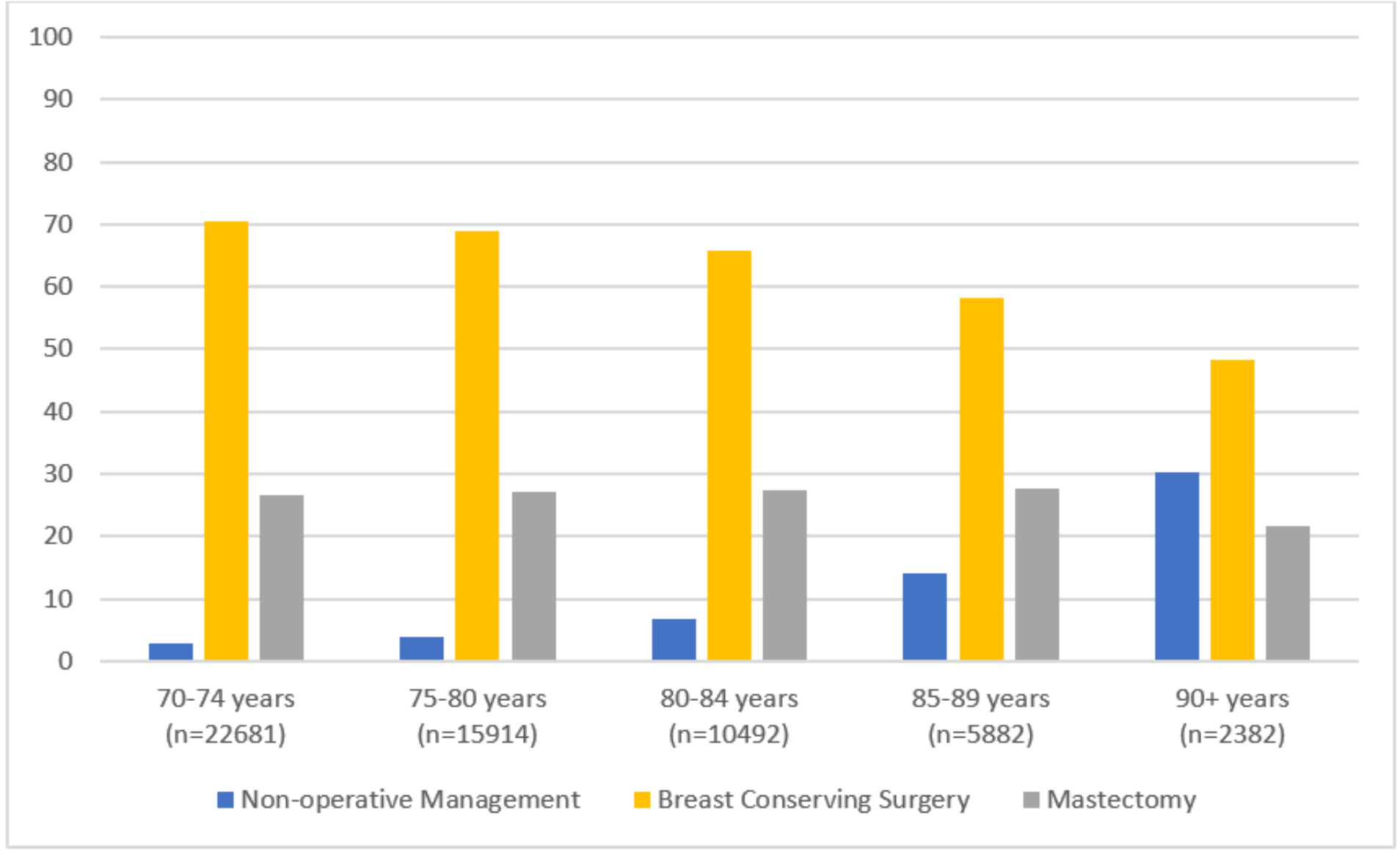

Figure 1 
Surgical management by age group in older women with stage I-III Hormone Receptor Positive/HER2negative invasive breast cancer.

A)

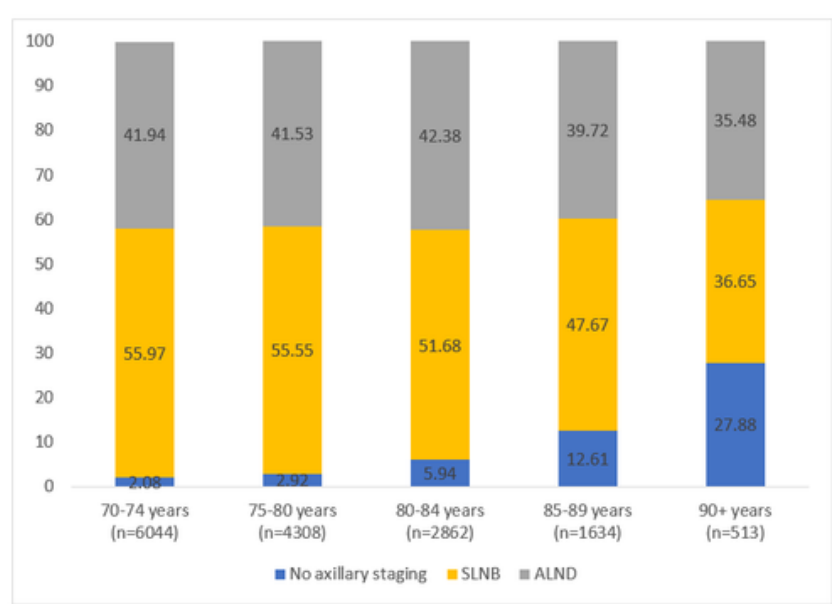

B)

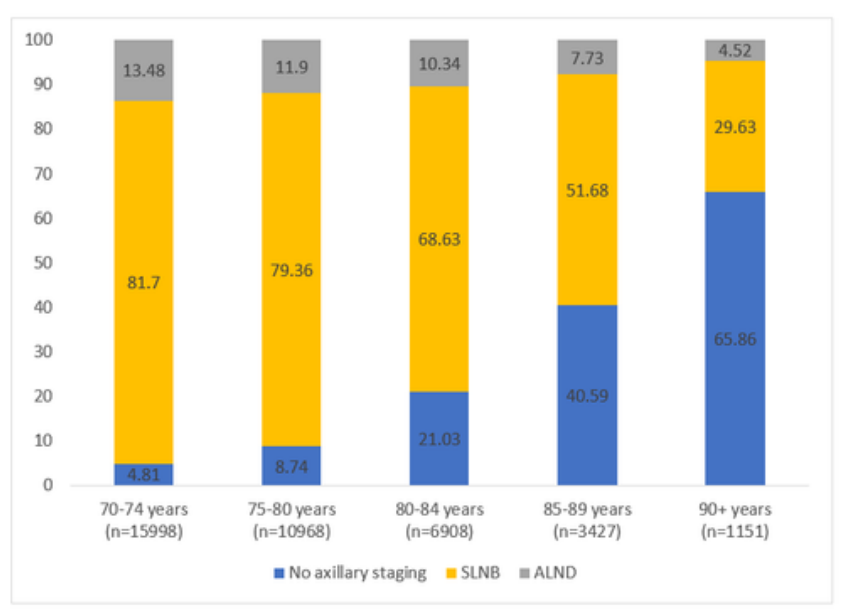

C)

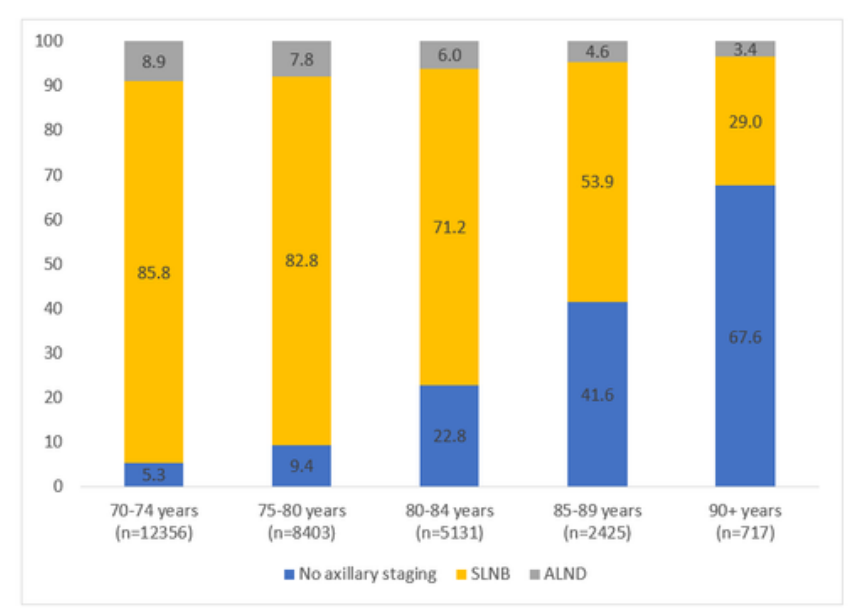

Figure 2

Axillary surgery by age group in women undergoing surgical management for Hormone-receptor positive, HER2-negative invasive ductal carcinoma. (A) Patients undergoing mastectomy for stage I-III breast 
cancer; (B) Patients undergoing breast-conserving surgery for stage I-III breast cancer; (C) Patients undergoing breast-conserving surgery for stage I breast cancer.

A)

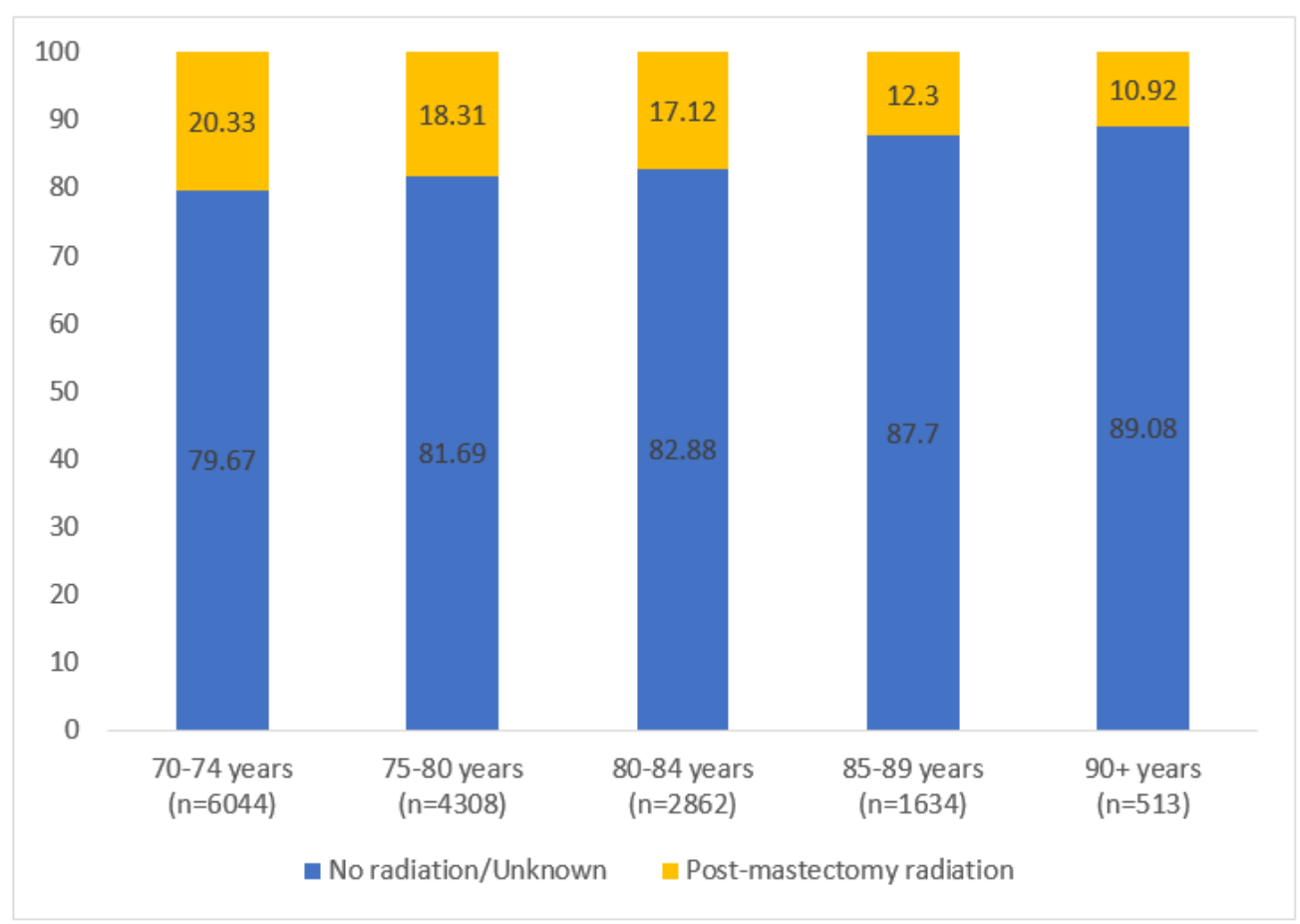

B)

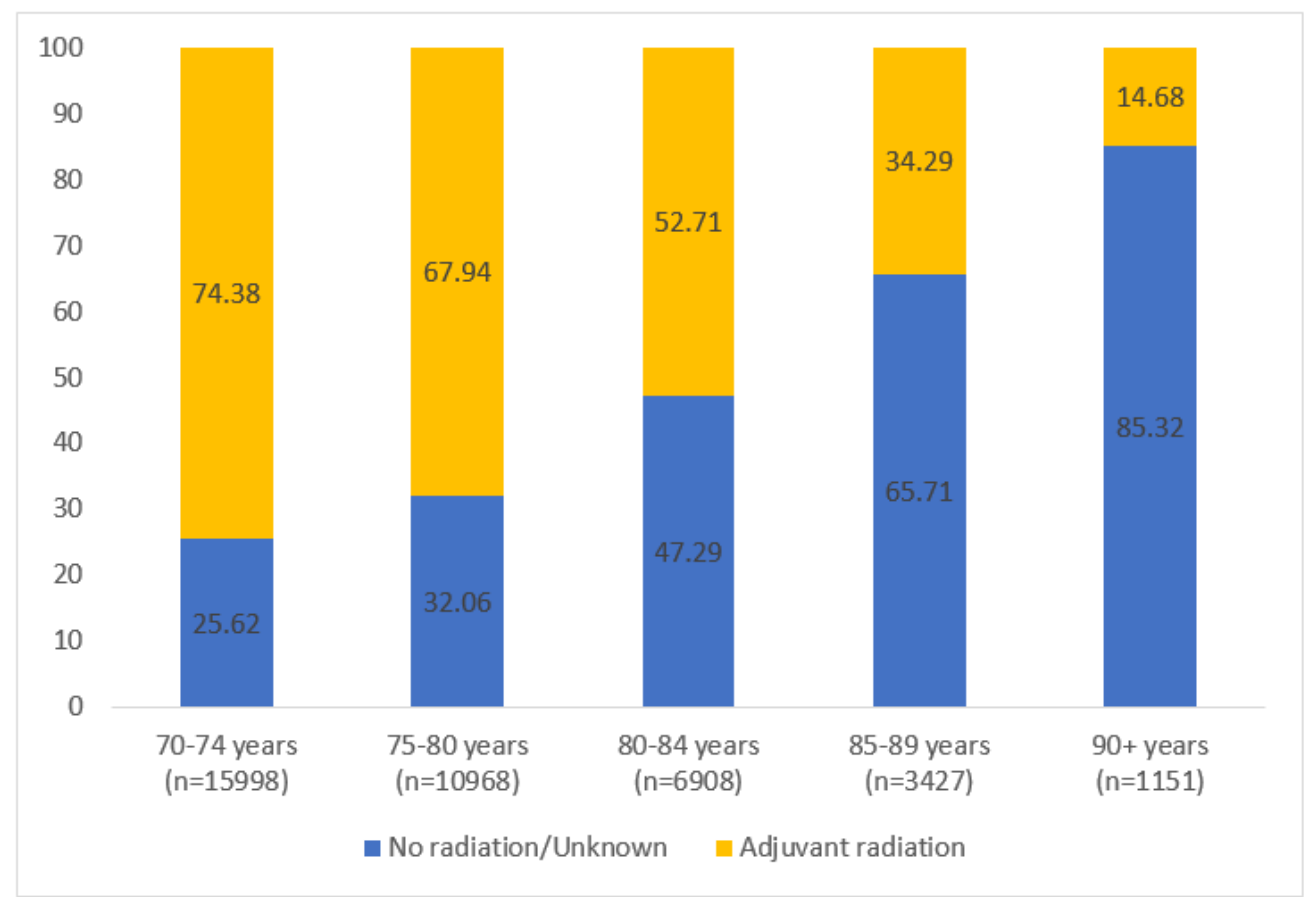

\section{Figure 3}

Adjuvant radiation by age group in women undergoing surgical management of stage I-III HormoneReceptor Positive, HER2-negative invasive ductal carcinoma. (A) Patients undergoing mastectomy. (B) Patients undergoing breast-conserving surgery. 